\title{
The significance of non-invasive methods of document examination in evidentiary proceedings
}

\author{
RAFAL CiEŚLA \\ ORCID: 0000-0002-8479-288X \\ Department of Forensic Sciences \\ Faculty of Law, Administration and Economics \\ University of Wrocław, Poland
}

\section{Introduction}

Thanks to the development of examination methods, evidence provided by forensic examination of documents has acquired a greater significance. A demand for expert opinion in this area has increased not only in penal but also in civil and administrative court cases, which may result from increased awareness of the parties in the proceedings of the potential offered by scientific examination of documents. The implemented analyses involve interdisciplinary research, whose scope always depends on the circumstances of the case and the decision of the body commissioning the examination, comprising handwriting examination of e.g., texts, signatures or initials, on the one hand and on the other - examination of ink, paper, pens and mechanical appliances, such as printers and photocopiers. Technological and technical progress resulting in new and alternative solutions in creation and circulation of documents, including electronic ones, necessitates constant effort in improving the methods of document examination. The latter concerns difficult cases involving, e.g., determining the age of a document or the kind of ink used in creating it. In penal, civil and administrative court cases a document

Nowa Kodyfikacja Prawa Karnego 51, 2019

(C) for this edition by CNS 
is very important and frequently constitutes the only evidence confirming or contradicting the circumstances of the case. Civil proceedings assume two presumptions concerning official documents: firstly, their credibility, i.e., they are congruent with the circumstances which they testify to and secondly, their authenticity, i.e., they do come from the issuer of the document, while the obligation to prove the contrary rests with the party contradicting the above presumptions. ${ }^{1}$ Due to the important role which they play, documents fall victim to the offences against their authenticity and in such cases examination focuses on their material aspect (ink, paper). The problem concerns all kinds of evidential proceedings, even though a document may play different roles in different procedures. The most important issues for the body commissioning the examination are that the evidence — the document in question - is not destroyed or damaged and that the expert opinion is unambiguous and categorical. However, the latter condition cannot always be met as the methods implemented in the examination sometimes vary dramatically, while their effectiveness is sometimes limited (which also results from the quantity and quality of the examined material). Ultimately, the most common problems faced by an expert are whether a document or a few documents were drawn with the same ink or whether a document was drawn on the date which it bears; the latter frequently involves determining the time when the ink was applied on the paper.

\section{Material, methods and research}

This article discusses effective implementation of non-invasive spectral methods to determine the homogeneity of ink used to draw a document.

The examination aimed at determining whether the signature "Her... Fieb..." and the series of figures " $3 \ldots .02 \ldots 13$ " above it were written in the same ink. ${ }^{2}$

Confrontation of non-invasive methods implemented in the examination led to interesting conclusions. Visual examination of the document

1 M. Leśniak, Wartość dowodowa opinii pismoznawczej, Pińczów 2013, p. 160, after the ruling of the Polish Supreme Court of 15 September 2009, I CKN 1436/00, LEX no. 583712 .

${ }^{2}$ Decision of the Polish District Court in Nowa Sól in the case 1572/10.

Nowa Kodyfikacja Prawa Karnego 51, 2019

(C) for this edition by CNS 
(a white sheet of A4 paper) proved that it was a photocopy of an official form, whose spaces were filled in by hand. On the right there were two signatures one above the other: the space for the husband's signature was filled in with the words "Her... Fieb..." in black ink and underneath there was the wife's signature "Jad... Fieb..." in blue ink in the space provided. The figures were written in black ink. The examination focused on qualitative analysis of the inks and homogeneity of the paper. Following the adopted routine, initial analysis of the document implemented spectroscopic methods involving a video spectral comparator VSC2000/HR, ${ }^{3}$ which enables examination of documents in various lighting conditions and at different optical magnifications (Fig. 1 and Fig. 2). ${ }^{4}$

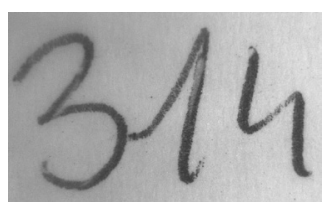

Figure 1. Fragment of a handwritten date on the examined document in visual light enriched with infrared at maximum optical magnification of the VSC2000HR

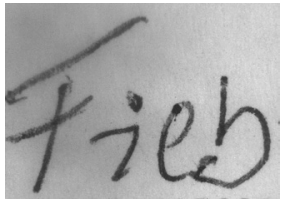

Figure 2. Fragment of a handwritten signature on the examined document in visual light enriched with infrared at maximum optical magnification of the VSC2000HR

The examination involved observation of the paper in the spectrum of light from near infrared through visual light (Fig. 3-6) to ultraviolet (Fig. 7-10) and in a light spot (Fig. 11-18) through a cut filter, which may reveal possible fluorescence of ink (or its residues on paper). ${ }^{5}$

3 Video Spectral Comparator, www.fosterfreeman.com (accessed: 10.09.2018); R. Kaur, K. Saini, N.C. Sood, "Application of Video Spectral Comparator (absorption spectra) for establishing the chronological order of intersecting printed strokes and writing pen strokes", Science \& Justice 53, 2013, no. 2, pp. 212-219.

${ }^{4}$ All the figures and tables were made by the Author, based on the materials provided for expert analysis in case no. 1572/10 of the Polish District Court in Nowa Sól.

${ }^{5}$ R. Cieśla, Technical Examination of Documents: Within the Scope of Polish Evidence Law, Wrocław 2006, pp. 144-146. 


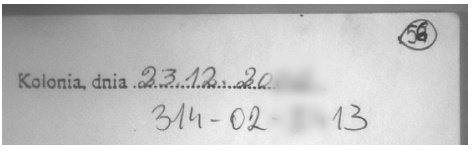

Figure 3. Fragment of a handwritten date on the examined document in visual light enriched with infrared

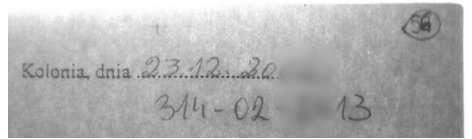

Figure 5. Fragment of a handwritten date on the examined document in transmitted visual light

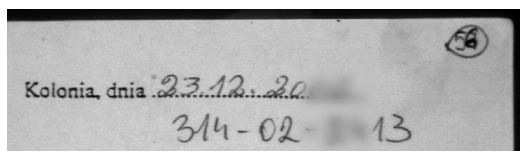

Figure 7. Fragment of a handwritten date on the examined document in long-wave (365 nm) ultraviolet

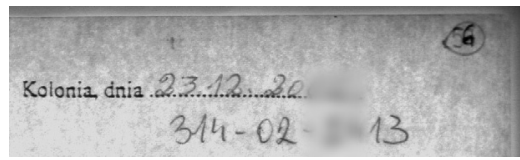

Figure 9. Fragment of a handwritten date on the examined document in transmitted ultraviolet

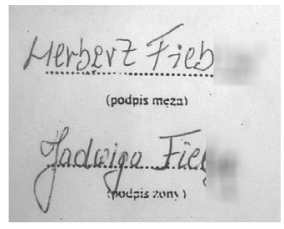

Figure 4. Fragment of a handwritten signature on the examined document in visual light enriched with infrared

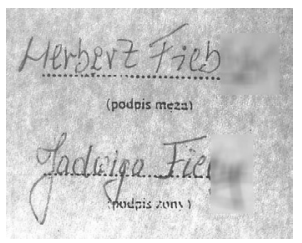

Figure 6. Fragment of a handwritten signature on the examined document in transmitted visual light

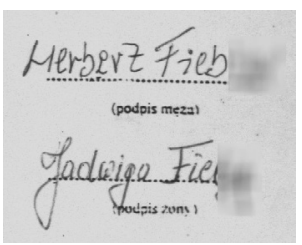

Figure 8. Fragment of a handwritten signature on the examined document in long-wave (365 nm) ultraviolet

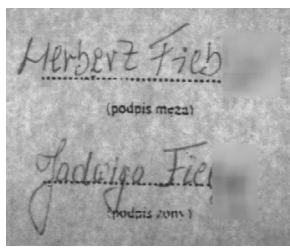

Figure 10. Fragment of a handwritten signature on the examined document in transmitted ultraviolet 


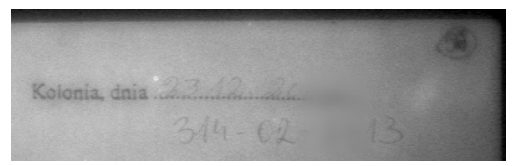

Figure 11. Fragment of a handwritten date on the examined document in monochromatic $(400 / 480 \mathrm{~nm})$ light spot seen through a $570 \mathrm{~nm}$ filter

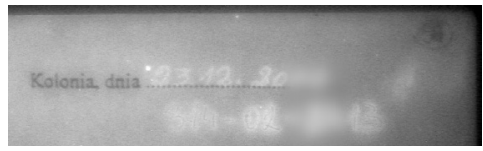

Figure 13. Fragment of a handwritten date on the examined document in monochromatic $(400 / 540 \mathrm{~nm})$ light spot seen through a $590 \mathrm{~nm}$ filter

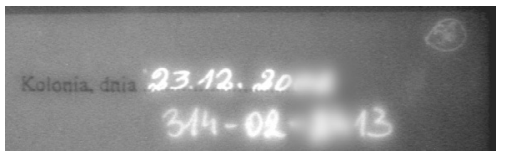

Figure 15. Fragment of a handwritten date on the examined document in monochromatic $(480 / 620 \mathrm{~nm})$ light spot seen through a $665 \mathrm{~nm}$ filter

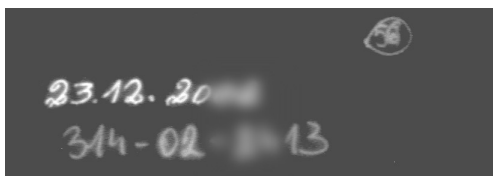

Figure 17. Fragment of a handwritten date on the examined document in monochromatic (530/660nm) light spot seen through a $715 \mathrm{~nm}$ filter

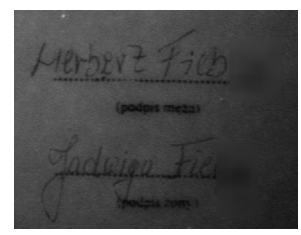

Figure 12. Fragment of a handwritten signature on the examined document in monochromatic $(400 / 480 \mathrm{~nm})$ light spot seen through a $570 \mathrm{~nm}$ filter

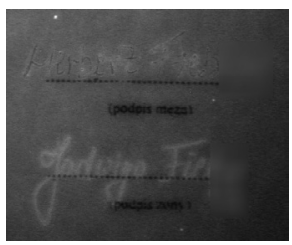

Figure 14. Fragment of a handwritten signature on the examined document in monochromatic $(400 / 540 \mathrm{~nm})$ light spot seen through 590 a nm filter

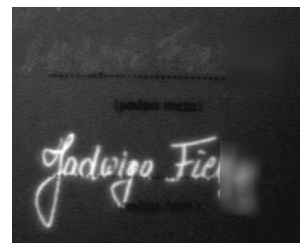

Figure 16. Fragment of a handwritten signature on the examined document in monochromatic $(480 / 620 \mathrm{~nm})$ light spot seen through a $665 \mathrm{~nm}$ filter

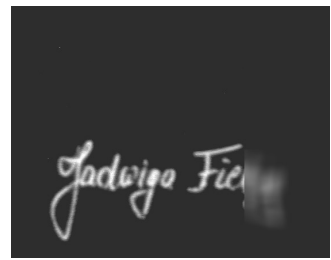

Figure 18. Fragment of a handwritten signature on the examined document in monochromatic $(530 / 660 \mathrm{~nm})$ light spot seen through a $715 \mathrm{~nm}$ filter

Nowa Kodyfikacja Prawa Karnego 51, 2019

(C) for this edition by CNS 
The analysis revealed differences in the fluorescence of inks. To confirm or reject the results obtained earlier, specialist equipment - a Polymorphic scanner for forensic examination of documents ${ }^{6}$ - was used. The scanner assesses similarity of colour properties in assigned wavelengths in selected fragments of a document and presents qualitative differences as the so-called "false colours" (Fig. 19-22).
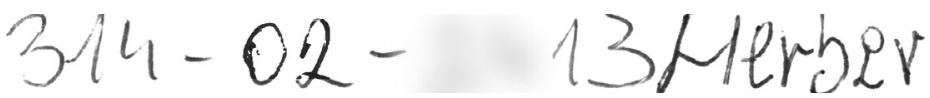

Figure 19. Selected from the spectrum of wavelengths which were used to differentiate selected fragments of the handwritten date and signature on the examined document

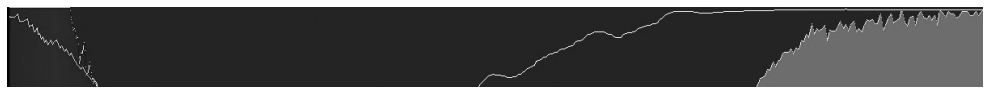

Figure 20. Views in "false colours" of selected fragments of the handwritten date and signature on the examined document

As seen in the illustrations, the examined handwritten entries were made in different types of ink.

The polymorphic scanner also enabled calculating the correlation between the spectrum of a selected fragment of the text and the mean spectrum adopted as reference. This type of examination assumes that the brighter the colour on the obtained images of the analysed fragment, the greater the correlation.
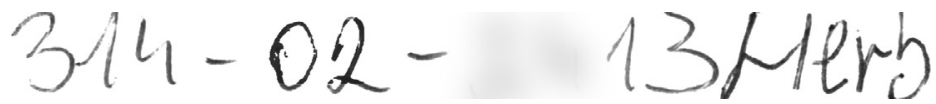

Figure 21. Fragment of the examined document selected for determining the correlation

${ }^{6}$ The specialist Polymorphic scanner for forensic examination of documents was constructed by a consortium formed for this research project: National Centre for Research and Development in Poland (NCBR), R00 002706 (Wrocław University of Science and Technology, University of Wrocław, KGHM Letia - now Technology Park of Legnica LETIA S.A.). See: G. Rusek, et al., "Polimorficzny skaner do kryminalistycznej ekspertyzy dokumentów w zakresie submikronowym", [in:] Znaczenie aktualnych metod badań dokumentów w dowodzeniu sądowym, eds. Z. Kegel, R. Cieśla, Wrocław 2012, pp. 299-309. 


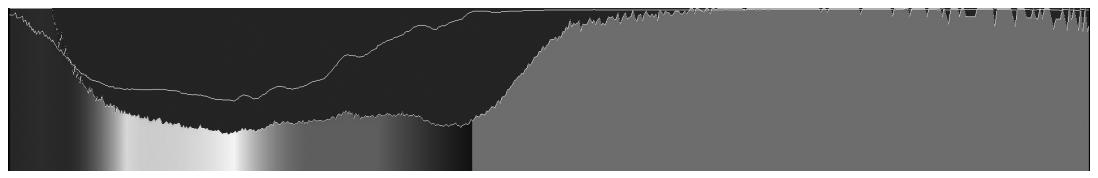

Figure 22. Mean spectrum (white line) used in calculating the correlation between the handwritten signature and the date

The correlation coefficient expresses a similarity between the examined elements numerically - the closer it is to one, the greater is the degree of similarity. For the examined document the values of the determined correlation coefficients varied between the minimum of -0.663237 and the maximum of 0.997701 . The obtained values of the correlation coefficients for selected fragments of the examined document are presented in Table 1.

Table 1. Values of correlation coefficient

\begin{tabular}{|l|c|c|}
\hline \multirow{2}{*}{} & \multicolumn{2}{|c|}{$\begin{array}{c}\text { Selected fragments of the examined } \\
\text { document }\end{array}$} \\
\cline { 2 - 3 } & $\begin{array}{c}\text { Figures: } \\
3 \ldots 02 \ldots 13\end{array}$ & Signature: Fieb... \\
\hline $\begin{array}{l}\text { Correlation } \\
\text { coefficient }\end{array}$ & 0.99024 & 0.79136 \\
\hline
\end{tabular}

Further steps of the examination consisted in obtaining electronic spectra. Relative to the needs of a particular case, absorption, reflectance and transmission spectra are obtained. In the discussed case spectrometric analysis measuring reflectance spectra was implemented with the use of video spectral comparator VSC2000/HR, which obtains electronic spectra of the lines written in ink and possible fluorescence spectra of inks. The latter are obtained after illuminating ink with monochromatic light of a particular wavelength (inducing luminescence) and observing the ink through a filter cutting off the inducing light. A number of reflectance spectra were obtained, which were later averaged (Fig. 23a and Fig. 23b). 


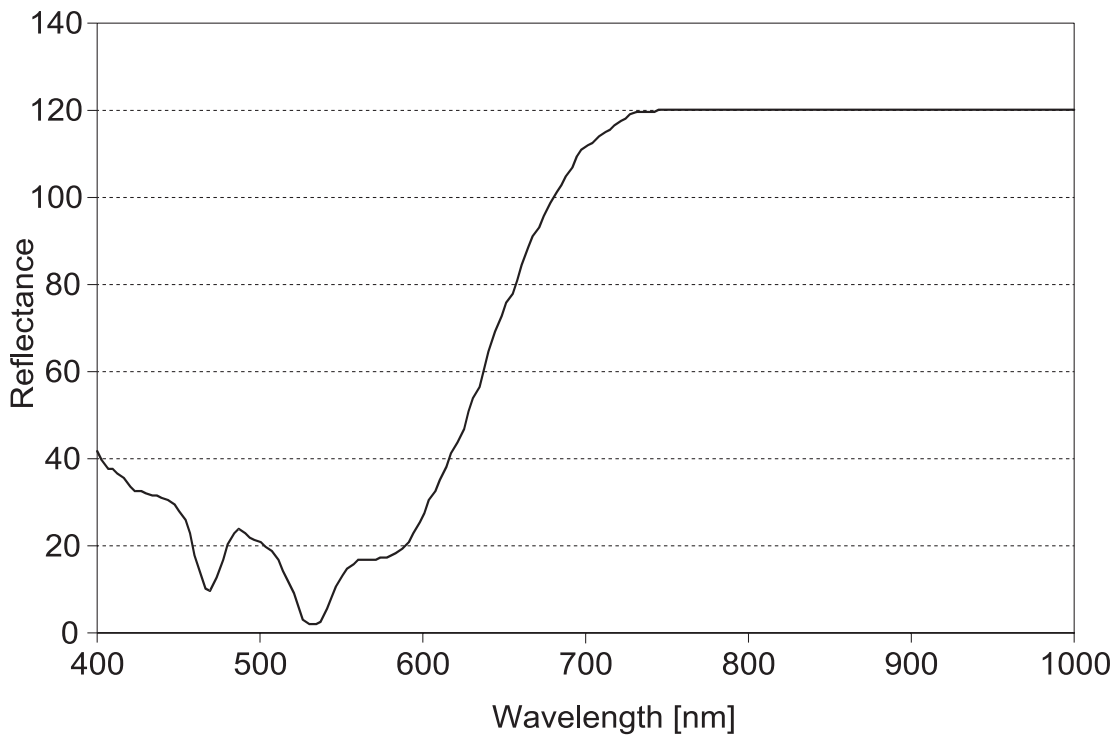

Figure 23a. Averaged reflectance spectrum of the figures " $3 \ldots 02 \ldots 13$ "

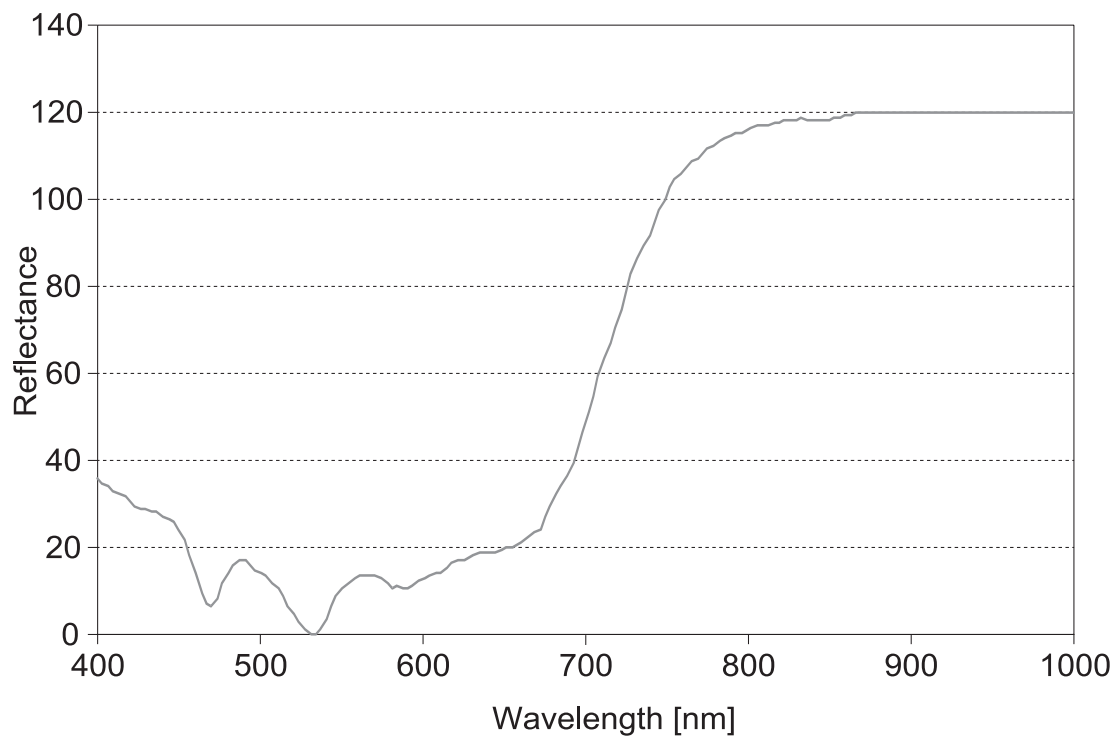

Figure 23b. Averaged reflectance spectrum of the signature "Fieb..."

Nowa Kodyfikacja Prawa Karnego 51, 2019

(C) for this edition by CNS 
Because the questioned entries on the document were written in black ink, the obtained spectra were plotted in one diagram for comparison (Fig. 24).

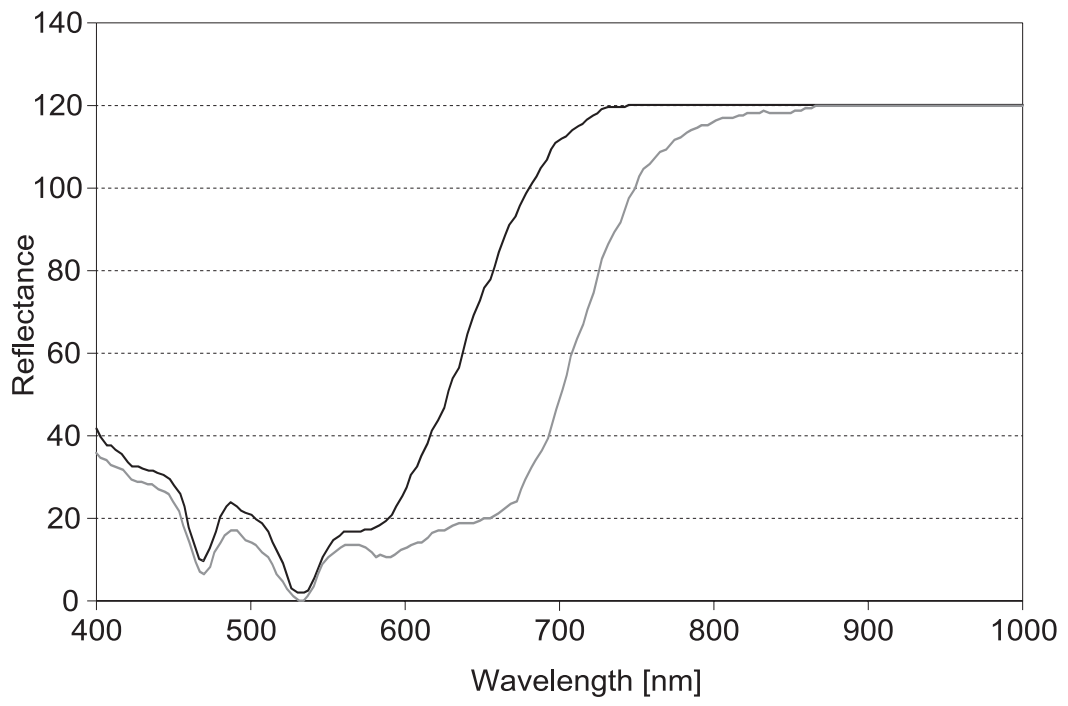

Figure 24. Comparison of averaged reflectance spectra of white light enriched with infrared of the inks of the handwritten entries on the examined document (spectrum " $3 \ldots 02 \ldots 13$ " and spectrum "Fieb...")

The spectra of the examined entries differ, which suggests that they were written in different inks. To highlight the differences, derivatives of spectra against a wavelength were obtained. The derivative cuts through the $\mathrm{x}$-axis at the point corresponding to the curve's maximum (Fig. 25).

The next step was the colorimetric analysis. The comparator VSC2000/HR has an algorithm calculating the values of parameters from the CIELab colour space ${ }^{7}$ for selected colour fragments. The obtained values of the parameters are presented in Table 2.

${ }^{7}$ M. McCormick-Goodhart, H. Wilhelm, "Progress towards a new test method based on CIELAB colorimetry for evaluating the performance of pictorial images", http://www.wilhelm-research.com/ist/WIR_ISTpaper_2004_02_MMG_HW.pdf(accessed: 10.10.2018); Wikipedia, "CIELab”, https://pl.wikipedia.org/wiki/CIELab (accessed: 2.11.2018). 


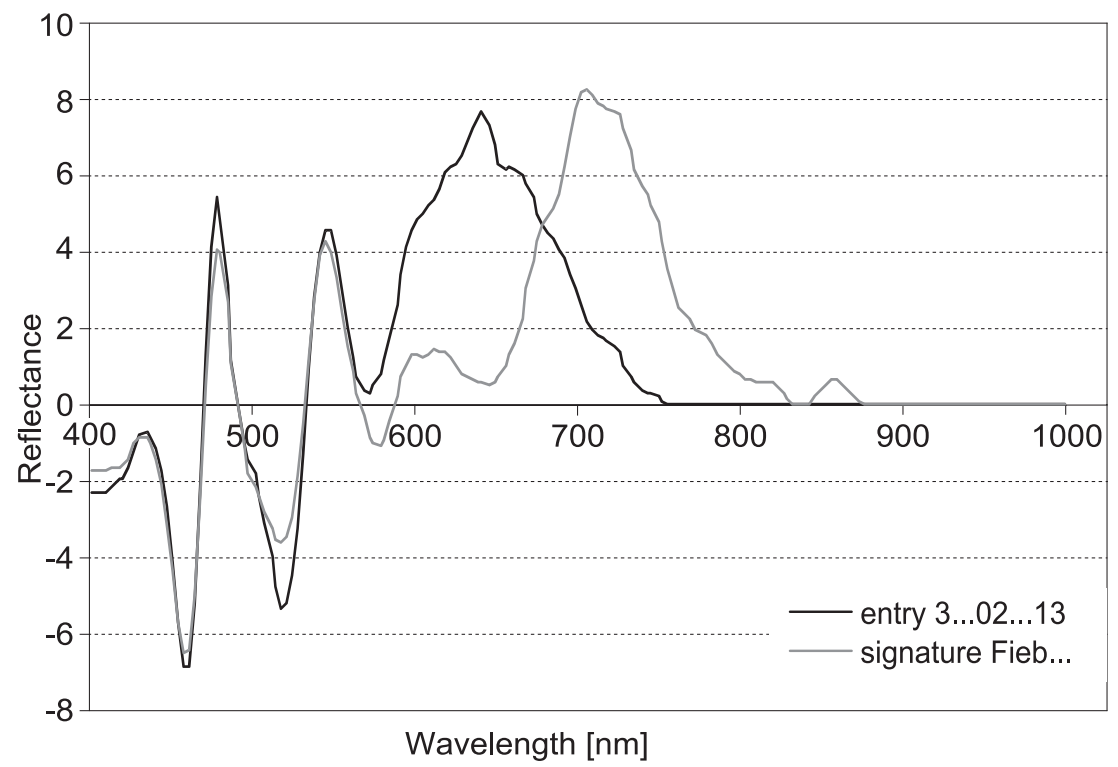

Figure 25. Comparison of averaged reflectance spectra of white light enriched with infrared of the inks of the handwritten entries on the examined document.

Table 2. Values of parameters of colour of the entries on the examined document

\begin{tabular}{|l|c|c|c|}
\hline \multicolumn{1}{|c|}{ Place of measurement } & \multicolumn{3}{c|}{ Parameters } \\
\cline { 2 - 4 } & $\mathrm{L}^{*}$ & $\mathrm{a}^{*}$ & $\mathrm{~b}^{*}$ \\
\hline $\begin{array}{l}\text { Averaged entry of figures: "3...02...13" } \\
\text { on the examined document. }\end{array}$ & 51.9 & 338.7 & 116.5 \\
\hline $\begin{array}{l}\text { Averaged signature "Fieb..." } \\
\text { on the examined document. }\end{array}$ & 39.2 & 266.2 & 94.6 \\
\hline
\end{tabular}

The values enable calculating the differences between the fragments according to the formula:

$$
\Delta E=\sqrt[2]{\left(\Delta L^{*}\right)^{2}+\left(\Delta a^{*}\right)^{2}+\left(\Delta b^{*}\right)^{2}}
$$

where: $\Delta L^{*}$ — denotes the difference between parameters $\mathrm{L}$ $\Delta a^{*}$ — denotes the difference between parameters a $\Delta b^{*}$ - denotes the difference between parameters b. 
Values of the differences between the fragments of entries on the examined document calculated according to the formula above are presented in Table 3.

Table 3. Differences of colour

\begin{tabular}{|r|c|}
\hline $\begin{array}{c}\text { Difference between entries } \\
\text { on the examined document }\end{array}$ & $\Delta \mathrm{E}$ \\
\hline "31...02...13" minus "Fieb..." & 76.79 \\
\hline
\end{tabular}

The difference in colour for values of $\Delta \mathrm{E}$ between 3 and 7 is assumed to be "perceptible" and for the values of $\Delta \mathrm{E}$ above 7 it is "distinct". The difference between the analysed handwritten entries on the examined document was 76.79, which confirmed the results obtained earlier.

For further confirmation of the results Raman spectrography was implemented. Spectroscopy in the range of visual light and ultraviolet, i.e., electronic spectra, primarily provides information on the colour composition of ink. Oscillation spectra, which include infrared and Raman spectroscopy, provide information on the structural elements of ink. The examination used Raman spectrometer FORAM 685-2, ${ }^{8}$ whose laser beam induces radiation of ink. While obtaining Raman spectra of the analysed inks, characteristic behaviour of the inks induced by the laser was observed. The groove made by the laser beam seen in the illustration confirmed earlier conclusions arrived at during the examination involving a stereo microscope that the document's template was photocopied by a monochromatic copier utilising thermal technology of fixing images (Fig. 26).
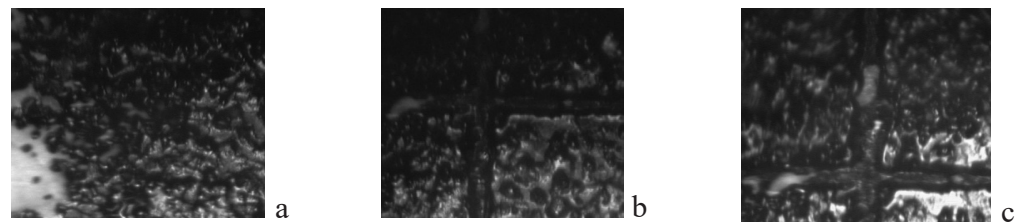

Figure 26. View of the printout on the examined document in the Raman spectrometer's

field of vision; a) in working light, b) "burning" of the groove in the toner with the spectrometer's laser beam (the red dot is the trace of the laser beam), c) the groove burnt in the toner after the laser is switched off

8 Raman Spectral Comparator FORAM685-2, www.fosterfreeman.com (accessed: 10.11.2018); R. Cieśla, Technical Examination of Documents: Within the Scope of Polish

Nowa Kodyfikacja Prawa Karnego 51, 2019

(C) for this edition by CNS 
Measurements of Raman spectra for the examined handwritten entries were made. After they were normalised, they were plotted in one diagram to compare the analysed spectra of inks (Fig. 27).

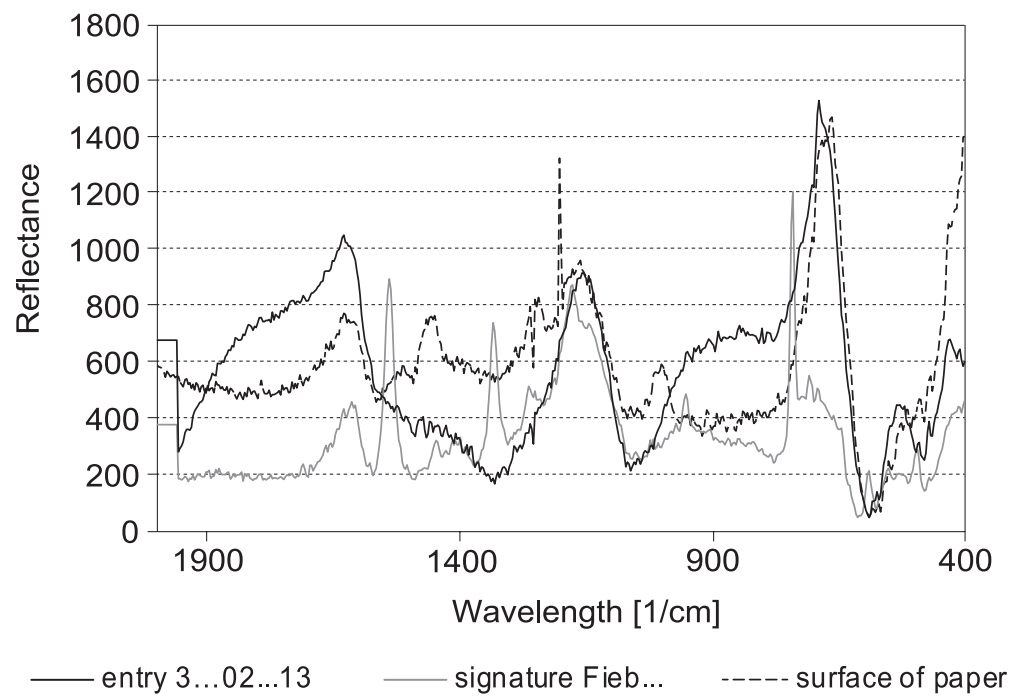

Figure 27. Comparison of averaged normalised Raman spectra of inks and paper on the examined document induced by the $685 \mathrm{~nm}$ laser beam

While Raman spectra were obtained, observation under a microscope revealed the presence of "black dots" scattered in the paper's structure. These are usually the traces left by commonly-used monochromatic photocopiers and some laser printers. However, the characteristic distribution of toner particles confirmed the hypothesis adopted earlier that the document's template was made on a monochromatic photocopier. The irregularly distributed "dots" are presented in Fig. 28. However, currently implemented technologies of paper production prescribe admixture of waste paper in the raw material and thus it cannot be ruled out that at least some "dots" testified to the presence of inadequately processed waste paper.

Evidence Law, Wrocław 2006, pp. 146-147; A. Braz, M. López-López, C. García-Ruiz, "Raman spectroscopy for forensic analysis of inks in questioned documents", Forensic Science International 232, 2013, no. 1-3, pp. 206-212. 


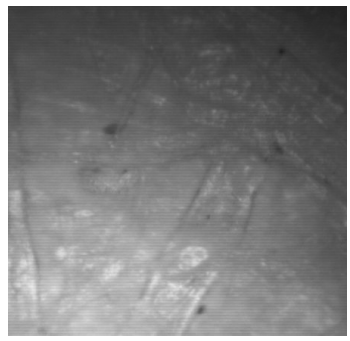

Figure 28. "Black dots" in the paper structure of the examined document

\section{Summary and conclusions}

The examination did not confirm any interference with the structure of paper in the places where signatures were written. Physico-optical examination of inks failed to determine any time relationships between the examined handwritten entries. These could only be determined with the use of physicochemical, damaging analysis of inks, which, however, was not the subject of this article. On the other hand, the analysis of images (Fig. 1 and Fig. 2) obtained during the examination proved conclusively that both examined handwritten entries (figures and the signature) were made with pens with ballpoint tips, i.e., commonly-used ballpoint pens. It also became apparent that two different pens with distinctly different inks were used (Fig. 15, Fig. 16, Tables 1-3). These conclusions were confirmed by optical analysis, especially the observation in a monochromatic light spot $(530 / 660 \mathrm{~nm})$ through the $715 \mathrm{~nm}$ cut filter (Fig. 17 and Fig. 18), spectral analysis of reflective spectra (Fig. 24) and the analysis of Raman spectra (Fig. 27). Non-invasive methods of document examination yield the results sufficiently accurate to prompt categorical conclusions as long as possibly the widest range of research methods is implemented. The inks were examined with a Polymorphic scanner for forensic examination of documents, which also confirmed the partial results obtained with the use of other methods.

Implementation of non-invasive methods results in conclusive expert opinion only if the objects analysed with the use of different techniques are considerably distinct in their character. Absence of clear-cut differences 
between inks may mean that the same ink was used or that different pens were used but their inks were made from the same ingredients and/or according to the same recipe; it may also mean that the methods implemented were not sufficiently effective to differentiate between the inks. Implementation of various techniques, including colorimetry, during one examination is necessary to verify the results yielded by particular methods, i.e., to confirm or reject the hypotheses made earlier. Confrontation of various non-invasive methods increases the chances of obtaining conclusive and convincing conclusions, enhances accuracy and objectivity of the examination results. The fact that the results of the methods discussed in this article may be presented visually is an additional advantage as they may be more convincingly presented to the parties in legal proceedings.

\section{References}

Braz A., López-López M., García-Ruiz C., "Raman spectroscopy for forensic analysis of inks in questioned documents", Forensic Science International 232, 2013, no. 1-3, pp. 206-212.

Cieśla R., Technical Examination of Documents: Within the Scope of Polish Evidence Law, Wrocław 2006.

Decision of the Polish District Court in Nowa Sól in the case 1572/10.

Kaur R., Saini K., Sood N.C., "Application of Video Spectral Comparator (absorption spectra) for establishing the chronological order of intersecting printed strokes and writing pen strokes", Science \& Justice 53, 2013, no. 2, pp. 212-219.

Leśniak M., Wartość dowodowa opinii pismoznawczej, Pińczów 2013.

McCormick-Goodhart M., Wilhelm H., "Progress towards a new test method based on CIELAB colorimetry for evaluating the performance of pictorial images", http:// www.wilhelm-research.com/ist/WIR_ISTpaper_2004_02_MMG_HW.pdf (accessed: 10.10.2018).

Raman Spectral Comparator FORAM685-2, www.fosterfreeman.com (accessed: 10.11.2018). Rusek G., Reiner J., Ptak R., Owoc M., Mrzygłód M., Cieśla R., "Polimorficzny skaner do kryminalistycznej ekspertyzy dokumentów w zakresie submikronowym", [in:] Znaczenie aktualnych metod badań dokumentów w dowodzeniu sądowym, eds. Z. Kegel, R. Cieśla, Wrocław 2012, pp. 299-309.

Video Spectral Comparator, www.fosterfreeman.com (accessed: 10.09.2018).

Wikipedia, "CIELab", https://pl.wikipedia.org/wiki/CIELab (accessed: 2.11.2018). 


\section{Summary}

Due to a document's important role in social interaction it is frequently forged or counterfeited, which has its impact on penal, civil and administrative legal proceedings. In the interest of evidential proceedings it is paramount that a document suffers minimum damage during an examination. Moreover, due to the need to implement various examination methods and the limitations of their effectiveness, the results of document examination sometimes fall short of expectations, which is reflected in the ambiguity of final conclusions. This article discusses effective use of non-invasive methods in forensic examination of documents. The presented case involved several non-invasive methods, including colorimetry. Confronting a few methods implemented in a particular case of document examination increases the accuracy and objectivity of its results and improves chances for formulating correct final conclusions.

Keywords: document examination, evidentiary proceedings, non-invasive methods, UV-VIS-NIR, colorimetry, polymorphic scanner, video spectral comparator, Raman spectral comparator. 